\title{
A Balanced Approach to Molded Case Circuit Breaker Maintenance
}

\author{
Mark T Babb, Andrew David Trusty \\ March 2019
}

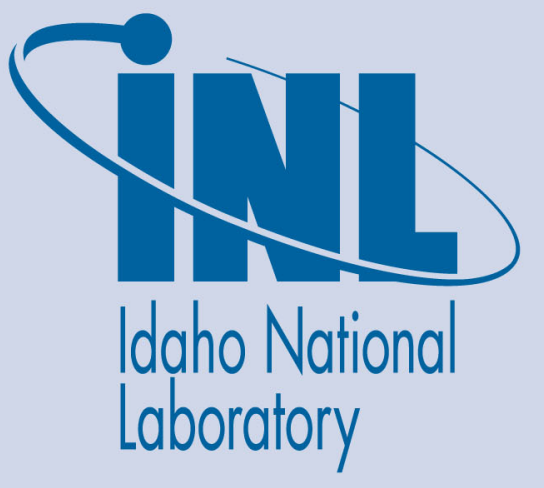

The INL is a U.S. Department of Energy National Laboratory operated by Battelle Energy Alliance 


\title{
A Balanced Approach to Molded Case Circuit Breaker Maintenance
}

\author{
Mark T Babb, Andrew David Trusty
}

March 2019

Idaho National Laboratory Idaho Falls, Idaho 83415

http://www.inl.gov

Prepared for the U.S. Department of Energy Office of Nuclear Energy Under DOE Idaho Operations Office

Contract DE-AC07-05ID14517 


\title{
A Balanced Approach to Molded Case Circuit Breaker Maintenance
}

\author{
Copyright Material IEEE \\ Paper No. ESW2019-41
}

\author{
Mark Babb, P.E. \\ IEEE Member \\ Idaho National Laboratory \\ Materials and Fuels Complex \\ Idaho Falls, Idaho \\ USA \\ Mark.Babb@inl.gov
}

\author{
Andrew Trusty \\ IEEE Member \\ Idaho National Laboratory \\ Materials and Fuels Complex \\ Idaho Falls, Idaho \\ USA \\ Andrew.Trusty@inl.gov
}

\begin{abstract}
NFPA 70E mandates that "overcurrent devices shall be maintained in accordance with the manufacturer's instructions or industry consensus standards". For national laboratories under the Department of Energy this mandate is law, because 10 CFR 851 requires adherence to NFPA 70 and 70E. This begs the question, exactly what are those manufacturer's instructions, and what do the industry consensus standards require? In particular with Molded Case Circuit Breakers (MCCB's), how does one meet these requirements and still apply a balanced approach in a maintenance program when the facilities range from brand new construction to over fifty years old, and where circuit breakers exist that have been made by virtually every major manufacturer?
\end{abstract}

This paper examines the instructions given by the various manufacturers, and examines the standards that exist, along with major guides and white paper recommendations. Both the consistencies and the inconsistencies are examined, recommendations are compared, and a general consensus of recommendations emerges. The various maintenance particulars are examined, from cycling of breakers and thermography to inverse thermal and instantaneous primary injection trip testing.

The results of an FMEA (Failure Modes and Effects Analysis) was conducted at our facility; the results of that FMEA and the recommendations of that FMEA for maintenance of MCCB's are presented.

In this paper, we have examined the recommendations of manufacturers, standards, and guides that provide the guidelines for maintenance of molded case circuit breakers. Although many conflicts exist, a consensus of nearly universal recommendations emerges. A balanced approach to maintenance that provides the maximum safety benefit within the bounds of economic feasibility can be developed. We provide a condensation of the existing literature with references, a visual summary of that literature and propose a recommended maintenance approach.

Index Terms - Manufacturer's Instructions, Industry Consensus Standards, Performance Testing, Inverse Time Overcurrent Trip Test, Instantaneous Trip Test, Molded Case Circuit Breakers, Failure Modes and Effects Analysis (FMEA), Reliability Centered Maintenance (RCM).

\section{INTRODUCTION}

Compliance with NFPA 70E "Electrical Safety in the Workplace" is gaining widespread acceptance and is now a requirement at our laboratory. Many years ago, before NFPA $70 \mathrm{E}$ addressed this issue and before consensus standards or most manufacturers addressed it, circuit breaker maintenance was an issue in the nuclear industry. Historically, one approach to maintenance of molded case circuit breakers 100 amps or greater, and many that are less than 100 amps, was to test and exercise them by primary injection testing for both inverse time trip and instantaneous trip on a three-year repeating basis.

In some cases, breakers were not removed from the equipment, and were tested by manually holding probes to the installed breaker on both input and output, and injecting either $300 \%$ of the rated current for inverse time trip testing, or $1000 \%$ of the rated current for instantaneous testing, or both. This allowed rapid testing of many circuit breakers, as the breakers were not removed from the panels or disconnected from their loads. Records regarding failure of the breaker to trip or not trip on the first attempt are not available, but anecdotal evidence exists in the form of reports by some electricians that the testing sometimes resulted in unreported initial failures of the breakers. Some estimates of the failure rate of breakers was as high as $0.5 \%$ and $2.0 \%$ per test, although no data exists to confirm this, as it was not deemed important enough to be recorded and tracked at the time. It was reported that breakers that failed the initial testing cycle were often retested successfully. This led to a practice of cycling the breakers immediately prior to testing, again because the impression of the electricians was that initial failures decreased if this was done.

The current practice of most of the engineers at our facility is to cycle breakers on a more frequent basis (ideally, annually), to perform "clean and inspect" procedures, and to utilize thermography for predictive maintenance. Routine injection testing is regarded as proof of operation and is required to ensure the maximum reliability of the circuit breakers that are used to limit arc-flash incident energy. The question is being discussed (and is a motivator for the study that is the subject of this paper) whether this testing (which stresses the breakers to an arguable degree) is more likely to find a fault that would cause a failure, or to cause a fault that would result in a failure. This was also the driver for the FMEA that was conducted, discussed in this paper. This is a matter 
both of risk assessment and of compliance to Standards and Codes.

This study summarizes the research into the meaning and intent of NFPA 70E with regard to the charge given in Sections 205.3 and 205.4, both of which state that equipment (and specifically overcurrent protective devices) "shall be maintained in accordance with manufacturer's instructions or industry consensus standards." These instructions and standards are listed and discussed and compared to each other and to the "Guide" that has overwhelming importance to them, specifically NEMA AB4. Both authors also participated in the FMEA that was conducted with regard to molded case circuit breakers.

\section{DISCUSSION}

\section{A. Manufacturer's Recommendations}

The authors were able to find only five major circuit breaker manufacturers that specifically published recommendations for the maintenance of molded case circuit breakers. To avoid commercialism, these manufacturers are listed here as $\mathrm{A}$ through E, in no particular order. Specific information regarding the source material is listed in the References.

Manufacturer A publishes several documents that provide guidance. The first of these is quite old; it offers trip curves to the reader "available on 10-1/2" x 15" translucent paper." This document clearly indicates that injection testing should be considered a "routine" test, but does not provide any guidance for how often this should be done. It differentiates between injection testing that is done routinely for "verification field testing" which "may have to be tested in the enclosure in which they are mounted," and "is not to determine if the breakers exactly meet published data" (emphasis theirs) and other testing. It nevertheless requires the size and length of conductors connected to the breaker specified "in the UL standard" to be connected. Instantaneous testing in particular is separated from "verification field testing" in that it "must be made in such a way that fields caused by the test equipment itself, steel enclosures, or the conductors from it to the circuit breaker do not affect the test results." In addition to injection testing, this document recommends insulation resistance testing, connection testing (inspection), contact resistance testing, and mechanical operation. This document also advocates using the "push-to-trip" feature of certain circuit breakers (which appears to be a new feature at the time) "because it will remove any dust accumulation on the mechanism and latch surfaces." [1]

Three installation instructions for specific MCCB's by Manufacturer A were published in 1990, 1995, and 1997. These installation instructions for specific products have a common "Maintenance" section, which states, "Generally there is no maintenance that is required but it is recommended that the following operations be performed annually," followed by instructions to clean and inspect the breaker and cycle it "several times" using the "slide to trip" lever to accomplish this. [2]

Manufacturer A publishes another recommendation, which simply states "Suggested inspection and testing is defined in NEMA AB 4-1996, 'Guidelines for inspection and preventive maintenance of molded case circuit breakers used in commercial and industrial applications'." [3] The date of
NEMA AB4 that is listed indicates that this document is about 20 years old (we are currently using the 2017 edition).

It should be noted at this juncture that we contacted several manufacturers of molded case circuit breakers that do not have any literature available and were told without exception that NEMA AB4 should be followed. This is the most common position taken today by the breaker manufacturers.

Manufacturer B encompasses at least three well-known name brands of molded case circuit breakers. This manufacturer recommends that circuit breakers be cycled annually "three times to ensure that all mechanisms are free and in proper working order." Beyond this, the manufacturer recommends "See NEMA AB4 for maintenance of molded case circuit breakers." [4] This manufacturer also publishes a 6-page document that reproduces Annex K of NFPA 70B for maintenance intervals of equipment that is notable in that it conspicuously omits the section of that Annex for molded case circuit breaker maintenance.

Manufacturer $\mathrm{C}$ provides the most detailed and most frequently updated recommendations for testing of molded case circuit breakers. This manufacturer recommends cycling breakers annually, using the "trip to test" function on the breaker whenever it is available. They also recommend periodic thermography and frequent inspection, which "can be performed any time electrical workers or maintenance personnel are in the vicinity of the electrical equipment." They state that "the standard generally used as a basis for field testing...is NEMA AB4," but recommend "Conduct performance tests only if inspection or daily operation indicates that a circuit breaker may not be adequately providing the protection required by its application." Performance testing is defined later as insulation resistance testing, inverse time overcurrent trip testing, instantaneous trip testing, rated current hold-in testing, and contact resistance testing. [5]

Manufacturer D provides recommendations for one of its products that falls under the MCCB genre that we could find. It recommends cleaning and inspection, cycling of the circuit breaker using the push-to trip button when available, and field testing those breakers equipped with secondary injection testing capability. All of this is to be done "periodically" with no specific period suggested, but "any field testing should be done in accordance with applicable NEMA Standard." This is clearly referring to NEMA AB4. [6]

Manufacturer $E$ provides guidance also for one type of its product lines that we were able to find. The push-to-trip button is "used to manually exercise the operating mechanism" but inspection and field testing "should be conducted in accordance with NEMA AB-2... also NEMA AB4...[7] (NEMA $A B-2$ is no longer available.)

Even a cursory look at manufacturer's instructions shows that most of them - and all of them that are reasonably recent - refer the user to NEMA AB4 as the standard by which field testing should be done. It is notable that several manufacturers specifically call out cycling the breaker as recommended; an apparent reason for this will become evident when NEMA AB4 is discussed in a later section.

\section{B. Industry Consensus Standards}

There are six standards - or publications that identify themselves as "standards" - that pertain to the subject of maintenance of molded case circuit breakers. Four of them 
are published by the IEEE, one is published by the NFPA, and one is published by ANSI/NETA. While all six have large areas of agreement, they also have specific areas of disagreement or ambiguity.

IEEE Standard 1015, commonly called the "Blue Book," states in its introduction that the only field maintenance that is normally done on MCCB's is inspection, cleaning, and checking for tight connections (7.3). It refers maintenance intervals to the NFPA 70B Annex $L$ (7.2) (which is specifically excluded as part of the NFPA 70B Standard by that Standard) which will be discussed shortly. It also provides justification for extending maintenance intervals based on a record of lack of failures (7.8), which is one of the principles of reliability centered maintenance (RCM), discussed in the FMEA section of this paper. NEMA AB4 is listed as a "normative reference" (6.10) and is said to be "indispensable for the application of this Standard." [8]

The ANSI/NETA MTS recommends in the Preface that "It is important to follow the recommendations contained in the manufacturer's published data." They make it clear that in order to do any maintenance of MCCB's, one needs to be trained and certified by ANSI/NETA and that other personnel are not qualified to do such testing. Maintenance that is listed as possible includes cycling, thermography, cleaning and inspection, injection testing, secondary injection testing, and various other tests (7.6.1.1). Methods for conducting tests are not detailed, for example, "Determine short-time pickup and delay by primary injection testing" is followed by the next step, "Determine ground fault pickup delay by primary current injection" with no substeps, details of how to do the test, or success/failure criterion. A table containing frequency of testing is contained in Appendix $B$, and "is recognized as a guide only", but the user is referred to a "NETA Accredited Testing Company for a reliability-based evaluation." Reliability Centered Maintenance (RCM) appears to be a primary thrust of this document, although specific instruction on or justification of its recommendations is sparse. NEMA AB4 is listed as an "applicable reference" (6.10) and is referenced in the tables for acceptable testing values, and the NEMA AB4 criterion for acceptable test results for injection testing are reproduced in this document. Molded case circuit breaker testing is lumped in with insulated case circuit breakers (ICCB's). [9]

IEEE Standard 3007.2-2010 emphasizes that the environment that equipment is subjected to is important and will "influence the frequency" of maintenance (4.2), and places emphasis directly on RCM (4.4). This standard is the most emphatic proponent of primary injection testing of MCCB's, which it considers to be "the only way to know whether the protective system works before it is needed" (5.1). It does not mention periodic injection testing, but states that if injection testing is not done for acceptance, then it should be done the first time maintenance is performed (4.4.4). It advocates failure analysis when a failure occurs (4.5.4), and recommends looking first to the manufacturer, then to NFPA 70B or ANSI/NETA for frequency of testing (4.6). With regard to injection testing, it first recommends following manufacturer's instructions, followed by "in the absence of manufacturer's instructions" testing per NEMA AB4, IEEE 1458, NFPA 70B, or ANSI/NETA (5.3). Thermography is advocated (5.4.5), and it mentions cycling of breakers as a "functional test" because of lubricant drying out, but oddly states that pivot points wear out because of lack of lubricant (5.3.2) [10]. (Most literature indicates that the lubricant in a circuit breaker may harden over time, impeding the free movement of components and potentially slowing down the reaction time or preventing the circuit breaker from operating under trip conditions. This is the reason given for annual cycling, which disturbs the lubricant and restores its lubricating properties. This document is the only one we found that states that wear is a factor.)

NFPA 70B contains much information useful for circuit breaker testing. It recommends "periodic" cycling using the trip-to-test button, if it exists (17.10). Annual or more frequent thermography is recommended (11.17.5), and the document speaks at length regarding Reliability Centered Maintenance (9.5, Chapter 30.) Inverse time trip injection testing is grouped with insulation and millivolt drop testing, but it is not clear from the text if this is intended to be "routine" or "special" testing. One of the authors made suggestions for changing this for the next iteration of NFPA 70B to specify that this was "special" maintenance, but this was rejected with the statement "Limiting the routine maintenance items proposed for molded circuit breaker routine maintenance are not sufficient for all situations. Molded case circuit breaker maintenance, inspection, and tests for the initial interval should not only be limited to mechanical on-off, thermographic inspection, and cleaning/inspection" (emphasis ours) [11]. "Special" maintenance is defined by maintenance conducted because of interruption of a high fault current (11.2.3). Instantaneous injection testing is reserved for "when calibration is required" which is difficult to reconcile with the fact that MCCB's cannot be field calibrated, and this test in no way provides any calibration data. Annex L, which is specifically excluded from being part of the $70 \mathrm{~B}$ Standard, provides recommended maintenance intervals for visual inspection and cleaning at 3year intervals, mechanical testing (cycling) at 2-year intervals, and "electrical tests" at 3 to 5 -year intervals. NEMA AB4 is cited as a reference for how to conduct preventative maintenance (11.10.2.1) and for testing (11.10.5.2.2). [12]

IEEE Standard 3004.5-2014 has limited but significant recommendations regarding $\mathrm{MCCB}$ maintenance. It recommends replacement of any MCCB that has interrupted near its AIC (fault current interrupting rating) twice (4.34), and defines what "abnormal conditions" for a circuit breaker are (5.6). It states that "limited maintenance is possible on larger frame sizes" (5.7) (the implication is that even less is possible on smaller frame sizes). It refers the user to NEMA AB4 for testing following a major fault trip $(4.34,4.35)$. [13]

The last Standard is IEEE Standard 1458-2017, which addresses the lifetime determination of an MCCB. Two recommendations are made that precede any other discussion, first that if there is any doubt about the condition of a circuit breaker, it should be replaced, and second that an MCCB that has been opened for any reason should never be re-used (8.1). "Non-destructive" test methods are listed, including primary injection testing for determining the functionality of circuit breakers for both inverse time trip testing and instantaneous trip testing. However, and this requires emphasis, in both procedures it is required and stated twice that the circuit breaker must be removed from the enclosure and tested on the bench in order to accomplish these tests. It should come as no surprise by now that this Standard also refers to NEMA AB4 for methods of conducting "periodic 
maintenance or during specific inspection following a high short circuit current fault" (8.1, Introduction). [14]

\section{The Pre-eminence of NEMA AB4}

It became obvious during our research that NEMA AB4 was considered by manufacturers and Standard writers alike to be the central reference to be followed in the maintenance of Molded Case Circuit Breakers. Even "competitors" of NEMA used this document as a reference. We found this to be unusual, because in legal proceedings, a Standard is normally considered to be a minimum engineering expectation while a Guide is considered to be an optional recommendation to be considered. In this case, NEMA AB4, "Guidelines for Inspection and Preventative Maintenance of Molded Case Circuit Breakers Used in Commercial and Industrial Applications" is the "go-to" document.

NEMA AB4 has two sections that detail what maintenance is done on MCCB's. Section 5 begins with a statement that "these steps are the only maintenance that should be performed on MCCB's unless specifically authorized by the circuit breaker manufacturer." The maintenance listed in Section 5 is limited: 5.2 is Environmental Evaluation, 5.3 is Interchangeable Trips, 5.4 is Wire Connections, and 5.5 is Reinstallation Procedure. Note that no routine maintenance on the actual circuit breaker is listed here.

Section 6 contains all the items that are thought of as MCCB maintenance and testing. Section 6 begins with this statement, "Some industrial users have indicated that they are required to conduct operational tests of their circuit breakers," and "The following non-destructive tests may be used to verify specific operational characteristics of molded case breakers..." followed by the list - 6.2 Mechanical Operation Tests, 6.3 Insulation Resistance Tests, 6.4 Individual Pole Resistance Tests, 6.5, Inverse Time Overcurrent Trip Tests, 6.6 Instantaneous Over Current Trip Test, and 6.7 Rated HoldIn Test.

Note that none of these tests in Section 6 are recommended. They are all permitted. This leads to the importance of the manufacturer's recommendations, since Section 5 says, "unless specifically authorized by the circuit breaker manufacturer." There are three maintenance items that are recommended by circuit breaker manufacturers; cycling the breaker, thermography, and cleaning/inspection. While not all manufacturers make all of these recommendations, those that recommend anything other than following NEMA AB4 tend to recommend these.

NEMA AB4 gives specific instructions on how to conduct these tests, including those in Section 6. These instructions include some very specific conditions that must be met in order to conduct performance testing: (2.2.4) "Before any functional tests are performed, be sure to connect the breaker to be tested with properly rated cable, torqued to the recommended values marked on the circuit breaker." A second admonition is given specifically for the inverse time overcurrent trip test and the instantaneous trip test, "Note: The circuit breaker should be removed from the equipment for this test. In cases where the circuit breaker can be safely isolated as installed the test may be performed with the circuit breaker in its equipment." This is augmented and clarified by a second step, "After being properly isolated, remove the breaker from the enclosure. In cases where the breaker can be safely isolated/disconnected from the line and load connections as installed, the test may be performed with the circuit breaker in its equipment." This requirement becomes yet clearer for the inverse time overcurrent trip test when the procedure specifies that the line and load connections must be connected to a four-foot length (or more) of properly sized cable, and that this cable must be properly torqued. (This last requirement is not specified for the instantaneous trip test). [15]

Following this procedure obviously removes the possibility of testing a circuit breaker by manually holding probes on the input and output of the circuit breaker while it is in place in the panel. Nevertheless, circuit breaker testing equipment manufacturers still manufacture and sell such probes, and this method is used by some testing organizations.

\section{A FMEA study summary}

In seeking to comply with the Standards above that place emphasis on Reliability Centered Maintenance, a special purpose facility at a national laboratory conducted a Failure Modes and Effects Analysis (FMEA) on Molded Case Circuit Breakers during the summer of 2016. This study was conducted specifically to determine what maintenance, if any, was warranted on MCCB's. The FMEA process is one of the analytical tools used in the RCM analysis process that has been used by industry since the 1970's. The FMEA focused on MCCB functions, possible failures, and severity of failures, specifically on 480 VAC 3 pole MCCBs (and representing the worst-case conditions,) without push-to-trip test buttons. The FMEA identified the functions of the MCCBs, functional failures, the components associated with the functional failures, the potential failure modes, the potential effects of the failure, the potential causes of the failure and any existing controls and their frequency. The standard method used to evaluate risk and the detectability of the potential failures was modified to adopt the NFPA 70E 2015 risk analysis method, and to take into consideration the specific concerns of NFPA. Every reasonable attempt was made to be thorough and objective; frequently, members disagreed strongly, but using the FMEA method were able to come to an objective set of conclusions that were shared by all. All members spoke frequently and freely with a high level of credence given to actual real-world experience.

The FMEA did not find that routine injection testing for either inverse time trip testing or for instantaneous trip testing was justified or outweighed the probability that such testing could result in an undetected failure. The primary benefit to such testing was determined to be the exercise of the tripping mechanism, which is not exercised by cycling the breaker unless the breaker has a push-to-test feature. For those breakers that do not have this feature and are critical for either arc flash protection or for protecting critical equipment from an overload condition, there was some justification for routine injection trip testing. The selection of which test to use (inverse time or instantaneous) was dependent on the function of the breaker, if it was decided to use testing. Some engineers considered the extremely small surface area in which lubricant would be disturbed by such testing to be unlikely to cause failure.

In summary, the FMEA recommended visual inspection and cleaning, thermography, and mechanical cycling, and recommended injection testing for acceptance testing prior to 
initial installation of new or replacement circuit breakers. A minority opinion favored routine injection testing of critical breakers (arc flash or overload) to exercise the tripping mechanism.

\section{E. White Papers Considered for this Study}

While the purpose of the study that is the subject of this paper did not include white papers, because several excellent publications outside of manufacturers and industry consensus standards exist and have been used at this national laboratory, we considered some of these. First and most important, we considered the work done and published by the Electrical Power Research Institute (EPRI) as published in "Molded Case Circuit Breaker Application and Maintenance Guide," Revision 2, which is a report rather than a peer reviewed journal, but contains a wealth of information.

Molded case circuit breakers are used extensively at nuclear power plants, which is the focus of the EPRI guide. The stated purpose of the EPRI guide is provide specific recommendations to allow development of a practical, cost effective, and technically sound MCCB maintenance program. EPRI found, in summary, that the most effective maintenance that could be done for MCCB's was thermography, visual inspection and cleaning, and mechanical operation (cycling), with the added possibility of electrical testing, including overcurrent testing "depending on the criticality of the equipment". The EPRI paper leaves the frequency of maintenance to the specific plant. While methods of determining "criticality" are discussed, the actual definition is left again to the specific facility.

Not surprisingly, NEMA AB4 is referenced in EPRI. One of the most enlightening items in EPRI is a correspondence with NEMA regarding questions that arose in EPRI when considering NEMA AB4. The response letter from NEMA, which was included as an Appendix to the report, includes some very poignant and direct answers to some difficult questions. Among these are the following points made by NEMA:

1) "Decisions related to the ability of the MCCB to protect the load must be made by engineering judgement." This was given in response to a series of questions arising from a MCCB that did not trip (on the high side) within the $+40 \%$ tolerance specified by NEMA, but the actual trip value was "well below the damage curve of the breaker's load".

2) While conducting injection testing of breakers in accordance with the NEMA guidelines is considered non-destructive, NEMA recognizes that an excessive number of operations will degrade any device. Additionally, extracting and replacing conductors in a pressure wire connector may leave the connection in an unknown condition due to distortion of the parts.

3) In response to a question about the necessity of instantaneous trip testing, NEMA stated that "MCCB's are designed such that they do not require maintenance for their service life." The test was included in AB4 because of reports that it was being done in industry, but "much of the same functional indication can be determined by the mechanical operation test in Section 5.2 of AB4". (Author's note: the mechanical operation test is in Section 6.2.)
4) Regarding the effectiveness of the $300 \%$ inverse time trip test, "As mentioned above, the mechanical operation test will provide much of the indication of functionality. The $300 \%$ inverse time overcurrent trip test will also demonstrate functionality of the latching system, contact opening and closing and mechanical operation." [16]

A NASA (National Aeronautics and Space Administration) "Lessons Learned" publication referred to "a situation (where) a vendor took used circuit breakers from various manufacturers, refurbished the exterior of the circuit breaker only, falsified circuit breaker data and sold them as new components." In this Lessons Learned, a circuit breaker that did not function was installed in a power panel. While the counterfeit breaker was discovered, it was considered a situation where a counterfeit breaker could have been installed in a critical application, resulting in a disaster. As a result, NASA recommended that all new circuit breakers be tested prior to installation to ensure that they are, in fact, circuit breakers as labeled. [17]

\section{F. A Final Caution Regarding Injection Testing}

It would be incorrect to conclude that the industry consensus standards and manufacturers do not encourage the use of injection testing in all cases, but this paper concentrates on routine maintenance only. Even a cursory examination of the manufacturer's instructions and industry consensus standards shows that they advocate injection testing to verify the effectiveness of a circuit breaker following the interruption of an unknown fault or of a fault that approaches the interrupting capacity of the circuit breaker. The reader is advised to bear in mind that the UL listing for MCCB's requires that they be able to interrupt current at their maximum interrupting capacity only twice. [18]

We would also be remiss if we did not mention secondary injection testing, where a signal is placed on the trip circuit simulating an overcurrent situation on electronic trip circuit breakers. This type of test is completely non-destructive, nondamaging, and is highly recommended as a routine test on electronic circuit breakers with that capacity. As the industry continues to evolve, we expect to see more and more of this type of breaker (as opposed to a thermal-magnetic trip breaker) and we look forward to seeing more secondary injection testing done on a routine and relatively frequent basis.

\section{Conclusions}

Molded Case Circuit Breakers are both commonplace and vital for electrical power distribution and safety. They provide much of the protection that is needed to prevent equipment damage and to protect personnel from the dangers of arc flash by providing rapid and effective removal of electrical power during overcurrent and short circuit conditions. They deserve and require maintenance.

They are also highly reliable devices that demand very little maintenance to ensure that they are functioning correctly. If a circuit breaker is kept in a good environmental condition, and is cycled annually, thermographically inspected periodically to ensure that it is operating correctly under load, and kept clean, it is likely to provide protection for many years. Circuit breakers 
that were installed 50 or 60 years ago are functioning much as they did when they were new.

However, they are physical devices with physical limitations. Engineering judgement is required to understand when a device that is subject to harsh environments, whether that is temperature extremes, exposure, humidity, chemical vapors, radiation, dirt or dust, or just hard or frequent use over time, needs to be replaced. Most of the time, this can be ascertained by normal maintenance - cycling the breaker and rejecting any breaker that exhibits unusual behavior or inspecting it and rejecting any breaker that exhibits burning, cracking, blistering, heating, or other abnormality. Sometimes it may be necessary for an engineer to test a breaker to be assured that it is operating correctly, but that should be rare. Most of the time, if there is any doubt at all about the functionality of a circuit breaker, it should be replaced.

With a clear disclaimer that the authors of this paper do not set policy for any national laboratory, we recommend annual cycling of circuit breakers as the primary maintenance on them, and that should apply to every circuit breaker (including the ones in your house panel). Thermography on commercial and industrial circuit breakers is easy, cheap, quick, and highly effective. There is no reason to fail to check a breaker at least once a year, and more often if it is a breaker that is used hard or has a critical function. Cleaning and inspection of circuit breakers in gentle environments should be done on a triannual basis, more frequently for those breakers in harsher environments.

Every circuit breaker that serves a vital function - whether it is overcurrent protection for important equipment or arc flash protection - should be tested prior to installation. The risk of getting a counterfeit breaker is too great to fail this step, and the initial test can be done easily in a testing rig, out of the panel. As an alternative, obtaining breakers from a trusted source and requiring a guarantee of authenticity can be used. We urge circuit breaker manufacturers to find a way to track breakers - serializing them and allowing them to be searched with regard to when they were made and where they were sold would be a good start. Ten years ago, that may not have been feasible but with the readily available data tracking capacity that we have today, it would be a minimal cost item compared to the benefit.

Periodic or routine injection testing of breakers to assure that they still work is questionable at best, since testing certainly causes wear and some degree of adverse change, even if it is not considered "destructive". When it is done, it should be done right - following the procedures that have been published - with an eye towards reliability centered maintenance. If it is to be done, and no failures are found, then extend the time between tests. Eventually, the data will prove how often this is warranted. For most applications, if a breaker is properly maintained according to the manufacturer's instructions and industry consensus standards by cycling, thermography, and cleaning and inspection, we believe testing will be warranted only once or occasionally twice in the lifetime of the breaker for most breakers.

Finally, we request that manufacturer's provide guidance in writing for the maintenance you recommend for your breakers. Saying "follow NEMA AB4" is not enough. We want to know what you specifically recommend for maintenance of your product. As engineers, we rely on you to provide us with the data that we need to make sound engineering decisions on what maintenance is done. From here, it appears that what we have recommended in this paper is what you want, but it also appears that many of you would prefer to place the onus on someone else for that determination. Fact is, if we have a choice, we will often select the breaker that has that technical information over the one that does not, and the better and more complete that information is, the more likely we are to select it.

\section{ACKNOWLEDGEMENTS}

We would like to thank Mr. William Closser of NuClear Services Group for his invaluable assistance in facilitating and directing the FMEA study that was done on molded case circuit breakers at the special complex of this national laboratory. We could not have reached this point without you, Bill. How you managed to get six engineers to agree on anything will always be one of life's greatest mysteries. 


\section{REFERENCES}

[1] General Electric GET-2963, "Testing and Maintenance of Molded Case Circuit Breakers," publication date unknown, entire document referenced.

[2] General Electric GEH-5591C (1990), GEH-5663B (1995) and GEH-5592E (1997) "Installation Instructions" for Spectra Series Molded Case Circuit breakers, entire documents referenced.

[3] General Electric GET-2779K 1000, "Molded Case Circuit Breakers, Application and Selection", 2000, pp 84.

[4] Eaton "Lighting and Distribution Panelboard Inspection and Maintenance Schedule Template", January 24, 2011, pp1-2.

[5] Square D "Field Testing and Maintenance Guide for Thermal-Magnetic and Micrologic TM Electronic Trip Circuit Breakers Class Number 0600, Instruction Bulletin 0600iB1201 R07/13, August 2013, pp 7, 9,12-17.

[6] Allen Bradley "Q-Frame Circuit Breaker Instruction Leaflet for Installation of Q-Frame Circuit Breakers", Bulletin 140U, publication 40752-078(1), effective May 2002, pp 6.

[7] Siemens Pc. No. 411381A00, EM frame, Types EM6 and EMK Circuit Breakers, Installation Instructions, pp 2.

[8] IEEE Standard 2015 "IEEE Recommended Practice for Applying Low Voltage Breakers Used in Industrial and Commercial Power Systems," 2006 Edition as appended by Corrigendum dated 2007, Sections 7.2, 7.3 and 7.8.

[9] ANSI/NETA MTS, "Standard for Maintenance Testing Specifications", 2015, Preface and pp 11, 67-68.

[10] IEEE STD 3007.2-2010, "Recommended Practice for the Maintenance of Industrial and Commercial Power Systems," 2010, pp 3-18, 29, 31, 34, 36.

[11] Public Input No. 60-NFPA 70B-2016 [Section No. 11.2.2], NFPA, Quincy, MA

[12] NFPA 70B "Recommended Practice for Electrical Equipment Maintenance" 2016, sections specified in the text, NFPA, Quincy, MA

[13] IEEE Standard 3004.5-2014, "Recommended Practice for the Application of Low-Voltage Circuit Breakers in Industrial and Commercial Power Systems," 2014, sections specified in text.

[14] IEEE Std 1458-2017 :"IEEE Recommended Practice for the Selection, Field Testing, and Life Expectancy of Molded-Case Circuit Breakers for Industrial Applications" 2017, sections specified in the text.

[15] NEMA AB 4-2017, "Guidelines for Inspection and Preventive Maintenance of Molded Case Circuit Breakers Used in Commercial and Industrial Applications," 2017, sections specified in the text.

[16] Electrical Power Research Institute, "Molded Case Circuit Breaker Application and Maintenance Guide", Revision 2, technical report. December 2004. EPRI, Palo Alto, CA

[17] NASA, "Lessons Learned, Maintenance and Test Criteria for Circuit Breakers" Lesson number 848, 1994-12-01.

[18] ANSI/UL489 "Molded-case Circuit Breakers, Molded Case Switches, and Circuit-Breaker Enclosures" $10^{\text {th }}$ edition, 04/25/2002.

\section{APPENDICES}

Appendix A. Flow chart showing manufacturers, industry consensus standards, and the requirements they contain.

Appendix $B$. Flow chart showing the centrality and detailing the requirements of NEMA AB4.

Appendix C. Flow chart showing the complexity and relationship between the sections of NFPA 70B.

\section{VITA}

Mark Babb, PE, graduated from Montana State University with a BSEE in 1987, and has painted with a broad brush since. He has worked as a laser damage testing engineer, electrician, electrical inspector, project manager, design and design/build engineer, forensic engineer, and is now the owner and principal engineer of Alethian Forensic Engineering. He is currently a registered professional engineer in 12 states, (but who's counting?) A relative newcomer (4 years) to this laboratory and IEEE, he works as an electrical engineer at a special complex of Idaho National Laboratory for fun and serves as secretary of the (new) IEEE ESC Codes and Standards subcommittee for entertainment. He can be contacted anytime at mbabb@alethianeng.com.

Andrew Trusty graduated from Temple University with a BSEE in 1986. He currently works as a systems electrical engineer at the same special complex at Idaho National Laboratory. With 28 years of experience in systems engineering at this laboratory, he now focuses on reliability engineering, thermography, arc flash mitigation techniques, and vibration analysis. He also keeps the feet of the other author of this paper firmly on the ground, which is no small task. 